\title{
ESTRATEGIAS Y RECURSOS PARA LA REELABORACIÓN DE UN POEMA HEROICO MEDIEVAL EN EL SIGLO XXI: LOS BEOWULFS DE ROBERT ZEMECKIS Y CAITLÍN R. KIERNAN
}

\author{
Juan Camilo Conde Silvestre
}

\begin{abstract}
RESUMEN
La presencia de la Edad Media como uno de los marcos privilegiados por la cultura popular contemporánea es fácilmente constatable en la cantidad de películas, novelas, cómics e incluso juguetes, videojuegos y hasta parques temáticos inspirados en distintos aspectos de este periodo de la historia europea. El poema anglo-sajón Beowulf no es ajeno a esta 'apropiación' y cuenta con decenas de (re)creaciones y adaptaciones en distintos formatos. Entre las más recientes destacan la película Beowulf de Robert Zemeckis (2007) y la novela homónima de Cailtlín R. Kiernan (2007), ambas basadas en el guión firmado por Neil Gaiman y Roger Avary (2007). En este trabajo se analizan estas dos propuestas, tanto desde los parámetros de la cultura popular, como en su relación con el poema medieval del que parten. De este modo, se detectan algunas estrategias literarias y culturales que remiten con cierta fidelidad al original y añaden así un componente intelectual o culto a estas dos versiones populares.
\end{abstract}

Palabras clave: Literatura medieval, literatura anglo-sajona, Beowulf, adaptación literaria, adaptación cinematográfica, cultura popular, intertextualidad.

\begin{abstract}
The Middle Ages has been privileged in countless adaptations within popular culture. The number of movies, novels, graphic novels, toys, computer games and even amusement parks based on different aspects related to this historical period is indeed very high. The anglo-saxon poem Beowulf is not an exception and there are dozens of adaptations or recreations which 'appropiate' the poem in different formats. Some of the most recent are the Hollywood movie Beowulf by Robert Zemeckis (2007) and the novel Beowulf by Caitlín R. Kiernan (2007), both relying on the script by Neil Gaiman and Roger Avary (2007). In
\end{abstract}

Fecha recepción: 5 febrero 2009. Fecha aceptación: 14 marzo 2009

1 Dpto. Filología Inglesa. Universidad de Murcia. Email: jcconde@um.es. 
this paper I study both proposals, firstly by looking at them from the perspective of popular culture and secondly by tracing their connections with the original Old English poem. This allows me to draw the literary and cultural strategies which link the adaptations to the original, thereby adding an intellectual component to the popular versions.

Key words: Medieval literature, anglo-saxon literature, Beowulf, literary adaptation, film adaptation, popular culture, intertextuality.

\section{INTRODUCCIÓN}

Resulta difícilmente discutible que la presencia del poema anglo-sajón Beowulf (siglos VIII-X) como texto heroico canónico y cuasi-fundacional de la 'literatura inglesa' ha contribuido a su constante ubicación en el acervo cultural colectivo de los países de habla inglesa. En los últimos tiempos, asistimos también a la absorción del texto hacia distintos ámbitos de la cultura de masas, incluyendo todos los formatos y géneros normalmente privilegiados en este entorno, desde el cine, el cómic y la novela popular, pasando por la música, hasta llegar a productos más próximos al artículo de consumo - juguetes, videojuegos, juegos de rol - en ocasiones pura mercadotecnia derivada de los formatos anteriores. Así lo atestiguan recopilaciones críticas y listados comentados de productos culturales, en su sentido más amplio, basados de algún modo en el texto anglo-sajón. En este sentido, la web Beowulfiana: Modern Adaptations of Beowulf, elaborada por John William Sutton, contiene entradas que se remontan a 1896 - fecha de la primera adaptación para niños conocida por el compilador: «Beowulf» de Mara L. Pratt, en el volumen Stories from Old Germany - y llega hasta 2007-2008: un auténtico 'año Beowulf', dada la repercusión de la película dirigida por Robert Zemeckis (2007) y de la novela homónima de Caitlín R. Kiernan (2007), basada en el guión cinematográfico (Gaiman y Avary 2007). El repertorio crítico elaborado por Sutton incluye referencias a los siguientes formatos, todos ellos encuadrados en la cultura popular: (i) novelas: desde las ya 'clásicas' Grendel de John Gardner (1971) o Eaters of the Dead de Michael Crichton (1976), hasta reelaboraciones pertenecientes a géneros variados (ciencia ficción, novela histórica, novela fantástica, cyberpunk, etc., con sus distintas hibridaciones), pasando por (ii) las consabidas adaptaciones infantiles; (iii) cine, incluyendo, además de la película de Zemeckis ya mencionada, The 13th Warrior dirigida por John McTiernan (1999), el Beowulf de Graham Baker (1999) o, más recientemente, la versión islandesa Beowulf and Grendel de Sturla Gunnarson (2005), y adaptaciones para televisión como Grendel de Nick Lyon (2007), o el episodio «Heroes and Demons» de la serie Star Trek: Voyager (Les Landau 1995), entre otras producciones; (iv) tebeos e historias gráficas, donde, entre otras, Sutton menciona y comenta las series clásicas de Michael Uslan —Beowulf: Dragon Slayer (1975-1976) - y el Beowulf de Jerry Bingham (1984), además de la adaptación de Gareth Hinds (Beowulf, 1999-2000) o la más reciente apropiación del personaje para el género manga en la serie Beowulf de David Hutchison (2006-2008); (v) música popular: un ámbito donde, además de los musicales Beowulf: A Musical Epic de Victor Davies (1974) y Beowulf. A Rock Musical de Ken Pickering y Keith Cole (1986), Sutton cita los discos editados entre 1980 
y 2007 por al menos tres bandas de rock que se autodenominan como el héroe medieval y hasta cuatro distintas bautizadas con el nombre de su primer antagonista, además de canciones sueltas como «Grendel» en la Essential Collection de Marillion (1996); la compilación incluye también (vi) una sección de juguetes, juegos de mesa, videojuegos, cartas y aditamentos para juegos de rol que se apropian del nombre y la caracterización de los personajes del poema, como Spycraft. Operation Nightfall (2004), MapleStory iTCG (2007-2008), Pirates of the Frozen North (2007-2008); y, finalmente, ofrece (vii) un apartado miscelánea, que contempla desde pins o colgantes con diseño e imágenes inspirados en el texto, hasta la marca de whisky escocés Grendel's Vatted Malt Whisky, pasando por la denominación informática Beowulf aplicada a la conexión en línea de varios ordenadores para aumentar su capacidad conjunta. ${ }^{2}$

Este asalto masivo y relativamente reciente al Beowulf por parte de la cultura popular, constituye para algunos críticos una «desacralización del poema» (Gómez Calderón 2002: 5), un «traslado de Beowulf desde el centro de la cultura hasta sus márgenes» (354), una apropiación, en suma, de su prestigio como icono de la tradición culta por parte del imaginario colectivo popular. Se trata de un proceso que cabe enmarcar dentro de otro más amplio de (re)creación de una nueva Edad Media, como referente histórico de límites difusos, cuyos contenidos - convertidos en leyendas fosilizadas en el ámbito de la tradición culta y bien asentadas en el acervo cultural común - atraen al gran público, sustentados por las modernas técnicas de mercadotecnia, y le ofrecen vías de entretenimiento, generalmente ajenas a su interés por el conocimiento del mundo medieval (Gómez Calderón 2002: 127). He aquí tres características comunes a estas recreaciones de lo medieval, compartidas también por la producción beowulfiana:

(a) Se trata en general de (re)creaciones de la Edad Media con una finalidad escapista, que responden a cierta «falta de conformidad con el presente» (Oleza Simó 1996: 94) y tienden a proyectar sobre las figuras y situaciones del pasado aspectos que se echan de menos en la sociedad occidental contemporánea: apelan a la simplicidad, la autenticidad, el primitivismo y los valores comunitarios como propios de una Edad Media idealizada y opuesta claramente al exceso consumista, a la tecnificación y competitividad individualista de la sociedad actual; o simplemente buscan la evasión a través de componentes mágicos y fantásticos. Ocasionalmente, en este panorama, se encuentran concesiones a

2 Véase también la recopilación de Osborn (1997) y, para estadios anteriores, además de la bibliografía de Hasenfratz (1993), Shippey y Haarder (1998) y la web Annotated List of Beowulf Translations, compilada por Osborn en <www.asu.edu/clas/acmrs/web_pages/online_resources/>. En nuestro país, Ma José Gómez Calderón ofrece una relación exhaustiva de esta producción beowulfiana popular en su tesis doctoral inédita Los 'otros Beowulfs'. Reelaboraciones contemporáneas (2002), donde también analiza algunas de estas novelas, películas y tebeos desde los parámetros de la cultura popular. También Bueno Alonso (2007-08) ha estudiado algunas recreaciones de Beowulf en formato cómic. Cabe señalar, con todo, que la recreación y adaptación de Beowulf, en particular, y de 'lo anglo-sajón', en general, no es novedosa y, como desvelan las contribuciones al volumen editado por Donald Scragg y Carole Weinberg, Literary Appropiations of the Anglo-Saxons from the Thirteenth to the Twentieth Century (2000), puede retrotraerse al periodo medieval tardío. De hecho, las reelaboraciones o recreaciones 'cultas' de clásicos anglo-sajones, en forma de novelas, poesía y, especialmente, teatro, jalonan todos los periodos de la historia de la literatura inglesa (véanse: Galván 1992; Frantzen y Niles 1997). 
planteamientos temáticos que pueden tener correspondencia con problemas actuales y ayudan a interpretarlos (Gómez Redondo 1990: 36-41; Gómez Calderón 2002: 90-91). ${ }^{3}$

(b) Hacer llegar la nueva Edad Media al gran público consumidor de la cultura de masas supone necesariamente simplificar sus contenidos, en muchos casos reduciéndolos a fórmulas o clichés. Desde la segunda mitad del siglo Xx se confirma cierta polarización de los estereotipos en los nuevos formatos de representación popular de la Edad Media: desde una imagen positiva que privilegia lo medieval cortesano, representado a través de caballeros y damas, aventuras y torneos, hadas y monjes bondadosos — la 'Edad Media caballeresca' - hasta la recreación de un mundo violento, inestable en términos políticos y sociales, asolado por epidemias, hambrunas, desorden y crueldad o rebosante de superstición y fanatismo: la 'Edad Media bárbara', considerada por algunos como una «visión realista» o como «representación de la verdadera cara medieval» (J.J. Alonso et al. 2007: 12; también: García Gual 1995). Se trataría, en todo caso, de propuestas contradictorias y, por extensión, incompletas o distorsionadas, aunque, en palabras de Gómez Calderón, «más reconocibles para la gran mayoría de los consumidores que la[s] descrita[s] en tratados académicos o en las propias fuentes medievales» (2002: 129). Desde la perspectiva post-modernista, son respuestas adaptadas a la llamada crisis de representación del sujeto. Además, desde estos planteamientos, la búsqueda cultural de un pasado cuyos límites también se disuelven en su propia construcción narrativa y textual supone una dificultad añadida para la representación de la historia, que tiende a admitir estas nuevas versiones estereotipadas (Jameson 1984: 59-60; Fradenburg 1997). Desde este punto de vista, la (re)creación de la nueva Edad Media en el ámbito de la cultura popular, como la de otros periodos históricos:

... es fruto de una situación histórica nueva y original en la que estamos condenados a perseguir la historia mediante nuestras propias imágenes pop y mediante los simulacros de esa historia que, por su parte, queda absolutamente fuera de nuestro alcance (Oleza Simó 1996: 82).

(c) La tercera cualidad común a este proceso de re-escritura o (re)creación de lo medieval, más directamente vinculada con el ámbito de la narración, tiene que ver con su formulación hipertextual, según la cual se vuelven a contar historias ya contadas desde nuevos puntos de vista (Fernández Prieto 1996: 214-215). Se trata de lo que también se denomina 'doble ficcionalización', según la cual el contenido de un producto medieval genuino se sitúa en el ámbito narrativo de la nueva Edad Media. No es poco habitual - fundamentalmente en el ámbito literario - que los textos medievales reelaborados en

3 Algunos miembros de la corriente medievalista francesa conocida como Escuela de los Anales, como Jacques le Goff, han recabado, en consonancia con su apreciación de la 'larga duración' (longue durée) de los tiempos históricos, esta presencia de lo medieval como clave para interpretar situaciones contemporáneas. En concreto, George Duby en su Año mil, año 2000. La huella de nuestros miedos (1995) recrea los paralelismos de las dos edades, especialmente en sus manifestaciones más violentas y descarnadas. Cabe preguntarse también hasta qué punto la presencia casi ubicua del monstruo - en sus distintas versiones - en la ficción popular contemporánea no responde a inquietudes propias de la crisis de valores que, para algunos, acompaña al cambio de milenio (véanse: Eco 1974; Warner 1994). 
los formatos y géneros propios de la cultura popular se vean despojados de su gravedad y carácter mítico o legendario, para ofrecernos lecturas distintas de los acontecimientos, recreadas a partir de lo que callaron las crónicas oficiales, versiones más humanizadas, cuando no parodiadas o transformadas en travestimientos o sátiras de los originales. También es común, en este entorno, su replanteamiento en términos fantásticos, dando prioridad a lo sobrenatural y lo mágico.

\section{LOS BEOWULFS DE GAIMAN Y AVARY (2007), ZEMECKIS (2007) Y KIER- NAN (2007)}

En su reciente y completa investigación sobre reelaboraciones contemporáneas de Beowulf, Gómez Calderón destaca la reescritura de las figuras en conflicto, el héroe y sus antagonistas, como el elemento que ha generado y mantenido el interés del público actual por el poema - independientemente de su propio conocimiento del ethos heroico medieval (2002: 177). En su formulación clásica — siguiendo a Propp (1955) - se trataría del enfrentamiento entre un hombre con capacidades y habilidades inusuales - aunque, generalmente, dentro de límites humanos - que, en defensa del orden colectivo, se enfrenta a un ser sobrehumano y monstruoso, cuyo fin es destruir las estructuras sociales y los valores de civilización que dotan de cohesión a la colectividad, sirviéndose de una maldad intrínseca y de poderes sobrenaturales destructivos; de este modo, el monstruo se sitúa en una posición liminal de alteridad con respecto a la vertiente humana (2002: 178). Esta presentación clásica se ha visto reelaborada desde dos perspectivas: por un lado, aquellas que «abordan el poema desde la intención transgresora y cuestionan el texto medieval como icono cultural por medio de la parodia»; por otro, las que tienen intención 'seria', con el objetivo de aproximar el poema «a la sensibilidad del gran público contemporáneo que [...] se acerca al texto movido por su curiosidad por lo medieval, el relato fantástico y los [...] estereotipos de la Edad Media inventada»(2002: 191). Entre los primeros, Gómez Calderón estudia algunos productos televisivos, otros difundidos por internet o adaptaciones musicales, como el mencionado Beowulf: A Rock Musical de Pickering y Cole (1980), además de cómics y relatos breves próximos al pastiche, como la colección «Beowulf: New Prose Translations» firmada por Ben Greenman para The New Yorker (2000). Las reelaboraciones que persiguen el segundo objetivo se decantan por los formatos cinematográfico o novelístico, como Grendel de Gardner (1971), Eaters of the Dead de Crichton (1976) o The Thirteenth Warrior de McTiernan (1999), amén de las novelas The Power of Beowulf de Parke Godwin (1995), The Legacy of Heorot (1987) y Beowulf's Children (1995) de Larry Niven, Jerry Pournelle y Steven Barnes o la versión cyberpunk True Confessions of a Dumpster Diver or Faster thru the Biofractal: A Cyberpunk version of the Beowulf Legend (2000) de McKinley Hill; todas ellas, y otrás, son analizadas de forma exhaustiva por la autora.

La película Beowulf de Robert Zemeckis (2007) y otros productos culturales de consumo derivados de ella (spin-offs), como, en concreto, la novela Beowulf de Caitlín R. Kiernan (2007), constituyen, en mi opinión, un caso interesante por dos motivos: primero, porque se trata de un proyecto que combina varios formatos usados por la cultura popular para sus reelaboraciones medievales; segundo, porque la recreación del mundo 
medieval que se acomete tiene muy en cuenta algunos aspectos del texto canónico, lo cual, junto a otros recursos literarios y culturales utilizados, les confiere un valor intelectual añadido. ${ }^{4}$

\subsection{Dos formatos con el mismo planteamiento}

La primera característica citada viene a redondear la cualidad de este producto como un 'conglomerado' propio de la cultura popular, basado en la combinación en este ámbito de distintos formatos. No se trata de algo inesperado, si se piensa en la relación entre novela y cine manifestada, en el mismo contexto de Beowulf, por la película The 13th Warrior (McTiernan 1999) basada en la novela Eaters of the Dead (Crichton 1976), e inspirada, entre otras fuentes, en el poema medieval. ${ }^{5}$ Lo interesante es que el caso que nos ocupa sigue el proceso inverso: a partir del guión original de la película, escrito conjuntamente por Roger Avary - ganador de un Oscar por Pulp Fiction (1994) - y el conocido autor y editor de cómics británico Neil Gaiman — también de la novela Stardust (1998), recientemente llevada con éxito a la pantalla por Matthew Vaughn (2007) —, se encargó a Caitlín R. Kiernan, una novelista de culto en los ámbitos de la dark fantasy y la ciencia ficción, la redacción de la novela homónima, publicada en 2007 por Harper Collins. ${ }^{6}$ Se trata, evidentemente, de una novela popular derivada de un guión cinematográfico basado en un poema medieval canónico.

Obviamente, la película de Zemeckis y la novela de Kiernan coinciden, pese a la diferencia de formato, en su línea argumental (Kaveney 2007; Allan 2009). La primera parte es, hasta cierto punto, fiel al texto medieval: el año 507 d.C. el anciano rey danés Hrothgar (Anthony Hopkins en la pantalla) y sus súbditos celebran ebrios la construcción de un nuevo salón comunal (hall). El jolgorio y la alegría resultan molestos para Grendel (Cris-

4 A estas dos cualidades cabe añadir la técnica cinematográfica utilizada en la versión de Zemeckis. De hecho, una de las novedades más aclamadas ha sido la técnica de 'captura de movimiento' - computer generated imagery (CGI) - ensayada previamente por el director en The Polar Express (2004) y anunciada en películas anteriores como Death Becomes Her (1992), Forrest Gump (1994) y Who Framed Roger Rabbit? (1998). Esta técnica permite combinar el trabajo de los actores con la animación digital: los primeros son equipados con centenares de sensores incorporados a su cuerpo y rostro de modo que todos los gestos y movimientos realizados al interpretar las secuencias se transmiten a ordenadores, desde los que se generan las imágenes digitales; posteriormente se añaden, también por ordenador, los trajes, la iluminación, los decorados, los efectos especiales, etc. En este sentido, la película, también estrenada en formato 3-D, constituye, según uno de sus críticos, «un espectáculo relativamente apabullante por su perfección formal y por la manera inteligente de integrar la pirotecnia tecnológica a las necesidades dramáticas» (Bermejo 2007: 54).

5 Sobre esta adaptación véanse: Guzmán González (1999), Magennis (2001) y Gómez Calderón (2002: 242-250).

6 Además de la novela, Harper-Collins publicó las distintas versiones del guión, Beowulf: The Script Book (Gaiman y Avary 2007) y se editó el volumen gráfico The Art of Beowulf (Cotta y Starkey 2007), con prólogo de Zemeckis e introducción de Gaiman. De hecho Kiernan - una autora prolífica, galardonada en cinco ocasiones desde que publicara Silk, su primera novela de éxito, en 1998 - ha colaborado con Gaiman en otros proyectos, como la serie de novelas gráficas The Dreaming, publicadas por DC/Vertigo Comics entre 1996 y 2001, y recientemente, de forma regular, en la publicación mensual Sirenia Digest o MerVISS, descrito en su página web como «a continuation of Caitlín's exploration of erotic literature with elements of dark fantasy and science fiction, creating brief, dreamlike fictions» (http://en.wikipedia.org/wiki/Caitlin_R._Kiernan). 
pin Glover), el semi-monstruo que escucha desde su escondrijo en una cueva cercana. Lleno de ira, Grendel ataca, destruye el hall y mata a varios guerreros, aunque perdona la vida a Hrothgar: de hecho, parece, por las miradas que en la película intercambia el rey con la joven reina Wealtheow (Robin Wright Penn), que hay razones ocultas que justifican el ataque. El edificio es clausurado hasta la llegada del gauta Beowulf (Ray Winstone) que, acompañado de un grupo de guerreros bajo las órdenes del lugarteniente Wiglaf (Brendan Gleeson), se ofrece a enfrentarse con el monstruo. Si bien estas reelaboraciones no coinciden con el original cuando presentan a Wiglaf como seguidor leal del héroe durante toda su gesta, y adelantan su presencia a la primera parte, ${ }^{7}$ le son fieles cuando tratan el desafío de Unferth (John Malkovich) y permiten que Beowulf narre con minuciosidad su lucha contra monstruos marinos durante la competición con Breca. Parece que Beowulf ha devuelto la normalidad a la corte de Hrothgar, y en el transcurso de una celebración - en la que también se percibe la atracción física de aquel por Wealtheow - el rey le ofrece como recompensa un cuerno de oro con forma de dragón: motivo recurrente que enlazará los distintos episodios en ambas narraciones. Terminada la fiesta, Beowulf se desnuda, como en el poema, para combatir al monstruo sin armas, mientras sus acompañantes cantan canciones obscenas con el fin de atraer a su enemigo. Finalmente, éste irrumpe en la estancia, matando y devorando a algunos guerreros, hasta que el héroe reacciona y se enfrenta con él: durante la encarnizada lucha consigue hacer estallar sus sensibles tímpanos y lo derrota arrancándole un brazo que, amputado, presenta como trofeo a los daneses. Grendel se refugia junto a su madre, a quien, antes de morir, relata en inglés antiguo - pues esta es la lengua de sus intervenciones - lo ocurrido. ${ }^{8}$

A partir de aquí aumentan las divergencias con el texto original. Durante la noche, después de celebrar la victoria, Beowulf sueña con la imagen de Wealtheow, quien trata de seducirlo pidiéndole la descendencia que no puede tener con el anciano rey Hrothgar. Cuando despierta encuentra que todos los guerreros - excepto Wiglaf, ausente - han sido masacrados, desmembrados y sus cuerpos cuelgan en las vigas de la estancia. Hrothgar informa al héroe de la existencia de la madre de Grendel y revela que fue fruto de un pacto secreto con ella: la razón también oculta de que el monstruo perdonase su vida en el primer ataque y del rechazo que la reina Wealtheow siente por su esposo. Beowulf acepta el reto de enfrentarse a este nuevo antagonista y recibe con dignidad la espada Hrunting

7 En la adaptación novelada de Kiernan y en la película Wiglaf es el compañero fiel de Beowulf durante toda su vida. Pero además la versión literaria se permite hacer un guiño irónico al original anglo-sajón, donde, como es bien sabido, Wiglaf será el único acompañante del héroe en su lucha contra el dragón:

-Y tú, poderoso Wiglaf, ¿todavía estás conmigo?

- Eres un idiota redomado por seguir a esa criatura hasta el cubil inmundo que le sirve de madriguera [...]

—-Indudablemente — replicó Beowulf —, pero tú estás conmigo.

Wiglaf se echó a reir de nuevo, una desesperanzada risa sin alegría.

- Hasta el maldito final -aseguró (Kiernan 2007: 173-174).

8 No deja de tener interés este recurso al inglés antiguo en breves frases o palabras sueltas que ocasionalmente salpican los diálogos entre Grendel y su madre - modor [madre], weorm [dragón, sierpe], faederleas [huérfano] - e incluso algunos fragmentos narrativos - weormgraf, en referencia al habitat de los monstruos, o aglaca [enemigo temible], aglacc-wif [mujer temible], como en el original, para describir a Grendel y a su madre. Se trata de la recreación de una lengua arcana y misteriosa con el objetivo de dotar a ambas criaturas de un halo también misterioso, recóndito y primitivo. 
que Unferth, como en el original medieval, le ofrece. En este punto, sin embargo, tanto el guión de Gaiman y Avary, como la novela de Kiernan, se encuentran bastante alejados del poema: cuando Beowulf entra en la ciénaga no va a enfrentarse con la poseedora de unas garras o de un largo tentáculo, insinuados en escenas anteriores, sino con una figura femenina bella y seductora (Angelina Jolie) que misteriosamente emerge desnuda de las aguas y, convirtiéndose en objeto de su deseo, derrota al héroe con promesas de gloria, poder y riqueza — «pride is the curse», reza el eslogan promocional de la película. Es sintomática la escena en que la espada Hrunting - con evidente simbolismo fálico - se derrite ante el avance y las caricias de la fémina. Beowulf regresa a la corte danesa y convence a todos de que ha derrotado a la madre de Grendel - para eso lleva consigo la cabeza de Grendel, pero no el cuerno de oro, que permanece junto a ella como prueba de un pacto secreto. Hrothgar, que no parece convencido de la victoria, proclama a Beowulf heredero del trono y, a continuación, se suicida lanzándose al vacío desde un torreón.

El desenlace, frente al poema medieval, tiene también lugar en Dinamarca, años después, cuando, tras derrotar a suecos y frisones, el anciano Beowulf se encuentra en la etapa final de su reinado. Se presenta ante él Unferth - sacerdote cristiano desde su conversión - quien le hace entrega de un cuerno de oro en forma de dragón que un esclavo ha encontrado en el páramo: el rey se percata enseguida de que la tregua con la madre de Grendel ha terminado y de que debe ahora «enfrentarse a sus demonios», como reza la carátula promocional española. Esa misma noche, el castillo sufre el ataque de un dragón gigante que, escupiendo fuego, abrasa a muchos guerreros y amenaza también a su esposa, la reina Wealtheow, y a Ursula, la joven amante del rey (Alison Lohman). Beowulf, acompañado de Wiglaf, se enfrenta al dragón: las escenas de lucha - como si fuesen las de un videojuego inserto en la película - presentan al anciano rey montado sobre el monstruo, buscando el modo de vencerlo, mientras éste, volando, vomita fuego sobre los guerreros que le lanzan inofensivas flechas y javalinas desde tierra; a la vez el dragón golpea su propia espalda contra las paredes de los acantilados para librarse de su molesta carga. Beowulf encuentra finalmente el punto débil en el pecho de su enemigo y tomando impulso trata de alcanzar su corazón para arrancarlo. En un gesto final de heroicidad, el protagonista fractura el hombro del brazo que lo sostiene, agarrado a la cerviz del dragón, a fin de ganar los centímetros que necesita para llegar hasta el órgano; cuando lo consigue, ambos caen, heridos de muerte. Mientras agoniza, con su brazo amputado, como antes Grendel, Beowulf observa que el dragón adquiere fisonomía humana antes de desaparecer.

La escena final muestra a Wiglaf que, como nuevo rey, preside el funeral de Beowulf. Conforme el barco en llamas que contiene su cuerpo se aleja por el mar - obsérvese la diferencia con el original-, Wiglaf reconoce la figura de la madre de Grendel que besa el cuerpo del héroe muerto. Seguidamente el oleaje deja a sus pies el cuerno de oro, que el rey recoge en un final abierto y lleno de ambigüedad.

Uno de los reclamos de estas dos versiones es, según su propia publicidad, que tratan de presentar el lado humano de los personajes, tanto porque dotan de voz a los antagonistas y proponen motivos para sus actos, como porque permiten vislumbrar algunos fallos en el comportamiento del héroe, de modo que, en palabras de Laura Gallego - autora del prólogo a la traducción española de la novela de Kiernan - «se nos brinda la posi- 
bilidad de leer la otra cara de la historia, la [...] de un hombre no del todo humano que se enfrentó a monstruos no del todo malvados» (p. 14). No se trata, realmente, de una novedad, ya que, como acertadamente señala Gómez Calderón (2002), la mayoría de las reelaboraciones contemporáneas para la cultura popular dotan a los personajes de una dimensión humana. Es suficiente, en este sentido, aludir a la conocida novela Grendel de John Gardner (1977), donde se da voz y perspectiva al monstruo, o a reelaboraciones más recientes como la novela The Tower of Beowulf de Parke Godwin (1995) donde, también según Gómez Calderón (2002: 225-230), las motivaciones del héroe salen a la luz tras un ejercicio de introspección psicológica en el que analiza las consecuencias de una relación frustrada con su padre Edgetho.

En este sentido, en las reelaboraciones de Zemeckis y Kiernan, los protagonistas masculinos - Beowulf y Hrothgar - muestran un comportamiento deshonesto y, por consiguiente, humano, en tanto que conscientemente tapan sus errores y ocultan, tras su jactancia y bravuconería, las razones auténticas de su actuación: el pacto que ambos sellan con la madre de Grendel y que supone el intercambio de descendencia asegurada para ella por poder para ellos. Por contra, según Syd Allan, los personajes femeninos - Wealtheow y, en particular, la propia madre de Grendel- serían íntegros y coherentes. De hecho, ambas reelaboraciones pondrían en primer plano el poder de las mujeres, enfrentadas por dominar a los varones, a quienes usan como títeres en su pugna. En este contexto neo-conservador, cabe interpretar la caída de Hrothgar y Beowulf como un castigo por quebrantar las leyes monógamas de fidelidad conyugal: «if the men would simply have sex with Wealtheow, instead of the witch, they'd have an heir and no monsters ravaging their land. Because they cannot stand strong in the face of temptation, and so remain monogamous, they lose everything including their pride» (Allan 2009). Esta explicación, finalmente, otorga consistencia a los motivos de los monstruos - añadidos al afán de venganza - en línea con otras reelaboraciones y adaptaciones contemporáneas, donde éstos representan el colapso de modos de vida habituales, en concreto, de todo aquello que «desafía a la familia como la estructura social más básica, asumida como 'natural' en el discurso de la ficción popular» (Gómez Calderón 2002: 299). De este modo, el personaje central en las versiones de Zemeckis y Kiernan es la madre de Grendel, promotora de la infidelidad y, a la vez, del castigo a los infractores, enviándoles el fruto maldito y monstruoso de su relación ilícita (Allan 2009). ${ }^{9}$

\subsection{Estrategias y recursos utilizados para la reelaboración del texto medieval}

Me interesa también profundizar en las relaciones de estas dos versiones con el texto original y en los recursos y estrategias que ambas utilizan - generalmente de forma coincidente - para trasladar algunos episodios del poema medieval al entorno cultural contemporáneo. Creo que este análisis puede, por un lado, ayudar a acotar la caracterización de un tipo determinado de reelaboraciones con objetivos y funciones coincidentes y,

9 Y sin embargo esta centralidad es del todo desconocida para la mayoría de los personajes, de modo que en la novela se dice, como un eco irónico y metatextual de la crítica actual sobre el poema medieval: «¿Y qué se supone que es la maldita madre de Grendel? ¡Si ni siquiera tiene un asqueroso nombre!» (p. 236) 
por otro, permite reconstruir, desde la perspectiva del receptor, el horizonte al que apelan y en el que se sustenta parte de su éxito. Trataré de destacar, de este modo, que, pese a su inserción en el ámbito de la cultura popular, la película de Zemeckis y la novela de Kiernan incluyen un componente intelectual o culto añadido, sólo desentrañable cuando se conoce su relación con el poema medieval.

\subsubsection{Recursos literarios: la intertextualidad como base de las versiones populares}

Uno de los recursos más característicos de estas dos versiones es su engarce intertextual con el texto heroico medieval, el cual, sobre la base del intento de «leer la otra cara de la historia», planteado como objetivo común a ambas, se ubica de forma recurrente como referente - hipotexto, en la terminología de Genette (1962) - necesario para interpretarlas. Así, el Beowulf medieval es mencionado explícitamente como la recreación literaria — estilizada y ficcionalizada - de la historia 'real' vivida por los protagonistas, la cual es efectivamente mostrada en la pantalla o narrada en la novela. Esta ironía especular, que permite incorporar la literatura 'seria' o canónica dentro del relato de ficción popular, se asienta, citando de nuevo el prólogo a la traducción española de la novela de Kiernan, en «la posibilidad de que el relato medieval no contara toda la verdad», en que «detrás de la leyenda $[. .$.$] hubiese una historia de mentiras y traiciones» \mathrm{y}$ «detrás del héroe hubiera un hombre como los demás» (p. 13).

Son varias las ocasiones en que las dos reelaboraciones juegan irónicamente con el Beowulf primigenio. Unas veces se anuncia o se prevé su futura cristalización como leyenda cuando la fama del héroe se extienda; así, la madre de Grendel le promete en la novela que su fama perdurará y que su historia será contada a las generaciones futuras: «Un hombre como vos será el protagonista de la leyenda más grande que se cuente jamás. La historia de vuestro coraje y vuestra grandeza existirá incluso cuando todo lo que ahora vive se haya convertido en polvo» (p. 197). Al final de la misma, Wealtheow repite, como un eco: «Su gesta original se contará mientras dure el mundo y los versos se recitarán de uno a otro confín» (p. 337). Más tarde, avanzado el reinado de Beowulf, se menciona la existencia de un poema - una saga - compuesto para celebrar la victoria del héroe sobre Grendel, recitado o representado - como efectivamente ocurre en la película - anualmente para conmemorar el acontecimiento. No hace falta decir que esta saga sería, en el imaginario que se propone, la base del poema medieval que, después de sucesivas versiones y revisiones, ha llegado hasta nosotros.

Un análisis detenido merece, en esta sección, el tratamiento de algunas digresiones del original. De hecho, un aspecto común a ambas reelaboraciones, donde este juego intertextual, no exento de ironía, alcanza mayor refinamiento, no se refiere tanto al poema Beowulf, como al único fragmento - cuarenta líneas escasas - de un poema anglo-sajón perdido conocido como The Fight at Finnsburgh. Como es bien sabido, el mismo relato está también inserto en el poema, extractado en el canto de un bardo durante las celebraciones en Heorot (11. 1107-1124); de ahí que las ediciones y traducciones del poema medieval incluyan como anexo el fragmento mutilado, cuyo destino editorial, literario y crítico está indisolublemente unido al de Beowulf. Las versiones de Kiernan y Zemeckis no son ajenas a esta convivencia en la historia de la literatura inglesa. Así, en la parte 
final se nos presenta, como epítome de su largo reinado, al héroe observando, junto a su fiel Wiglaf, el desarrollo de una batalla que enfrenta a sus tropas con invasores frisones. Estos últimos se hallan claramente en desventaja, cuando Wiglaf comenta: «Los frisones quieren ser héroes, señor. Pretenden que los bardos canten sus gestas» (pp. 220-221), en clara alusión al canto épico que habría de componerse sobre ellos y sólo ha sobrevivido de forma fragmentaria. El diálogo entre ambos continúa, inspirándose en la brevedad del fragmento conservado, su dependencia del texto que habría de convertirse en canónico y a su conocimiento en todo el dominio germánico, incluyendo la Gran Isla (Gran Bretaña):

- Será una canción corta - Beowulf suspiró y abrió los ojos de nuevo.

- Sí - admitió Wiglaf —, pero no podéis culparos. Vuestra leyenda es conocida desde los altos mares y las cumbres de nieve hasta el reino de la gran isla. Todo el mundo conoce el cantar de Beowulf y Grendel. Vos sois 'el que venció al monstruo' (p. 220)

Cuando los frisones están a punto de caer derrotados, su príncipe reta a Beowulf; el héroe, en otro guiño intertextual cargado de ironía, contesta:

-Así que queréis añadir vuestro nombre al cantar de Beowulf ... - dijo el soberano al frisón - ¿Acaso creéis que la balada concluirá con su protagonista asesinado por un estúpido de la Frisia que ni siquiera tiene nombre?

- Me llamo Finn - replicó el hombre - y soy príncipe entre los míos. Y mi nombre será recordado siempre... (p. 223).

Finalmente, Finn se rinde, intimidado psicológicamente por la valentía de Beowulf, que, sin armas y a pecho descubierto, lo incita a que termine con su vida. El héroe interviene de nuevo en clara alusión a la futura dependencia literaria del fragmento de Finn: «Dadle una moneda al príncipe y que vuelva con los suyos. Tiene una historia que contar» (p. 227). Se trata de una pugna que adquiere una dimensión culta añadida cuando se interpreta a la luz del corpus literario anglo-sajón: el enfrentamiento entre ambos personajes y la derrota de Finn frente a Beowulf deviene en la situación recogida por la historia de la literatura, en la que el breve fragmento de The Fight at Finnsburgh es subsidiario del Beowulf canónico.

Otra mención, más concisa, de las digresiones del texto medieval figura en la novela de Kiernan donde se refiere cómo Wiglaf, en el camino hacia la ciénaga, recuerda historias épicas legendarias:

Primero contó cuanto recordaba de una saga que había escuchado de uno de los escaldos de Hrothgar, de cómo una princesa danesa, Hildeburh, se casó con Finn, un rey frisón, y de las penas terribles y el considerable derramamiento de sangre que le siguió de forma inevitable, pero, aunque sabía que guardaba cierta relación con Jutlandia, se le olvidó el final y entonces se puso a hablar de las temerarias hazañas de Sigurd, el Matador de Dragones, y su espada Gram (p. 184). 
La primera alusión se basa también en el tratamiento de la historia de Finn en el poema medieval; el bardo centra su narración (ll. 1063-1162) en el papel de la princesa Hildeburh como peace-weaver - mujer dada en matrimonio como garante de la paz entre dos comunidades previamente enfrentadas - y en la fragilidad del pacto, reavivado cuando su hermano Hnæf visite tierras frisonas y desencadene la sangrienta batalla narrada en The Fight at Finnsburgh. La segunda hace referencia a otra conocida leyenda germánica, la de Sigemund y su combate contra otro dragón, también cantada por el scop en Beowulf (11. 867-915) a modo de adelanto, como en esta reelaboración, del enfrentamiento final del héroe. Esta misma mención se ve, sin embargo, replanteada en otras secciones. Así, cuando en la versión novelada se describe la cuerna de oro, se atribuye a Hrothgar su obtención como botín tras derrotar al dragón Fafnir (pp. 146, 150). De este modo, Hrothgar se apropia de la leyenda (y la figura) de Sigurd, ocultando el verdadero origen del objeto, como signo del poder seductor de la madre de Grendel y de su propia derrota en el pasado.

La relación intertextual con el poema medieval se explota también en la parte dedicada a Gréndel de las dos versiones contemporáneas. En ellas, además de replicar algunos contenidos del original, se aprovechan subtextos que el texto canónico sólo insinúa, a fin de contrastar las 'auténticas vivencias' de los personajes con la 'versión estilizada' que, en formato literario y manuscrito, habría llegado hasta nuestros días. Como ejemplo, cabe referir el episodio en que Hrothgar, cuando Beowulf se presenta ante él, recuerda el conocimiento que trabó con su padre, refiriendo la ayuda que él mismo le prestó al pagar la compensación (wergeld) que Ecgetheow adeudaba a los Wylfingos (ll. 457-490):

Siððan pa fæhðe feo pingode

sende ic Wylfingum ofer wæteres hrycg

ealde madmas; he me apas swor (11. 470-472)

Con mi pago sellé la disputa; envié antiguos tesoros a los Wylfingos por la inmensidad del mar y me hicieron el juramento. ${ }^{10}$

Este discurso de Hrothgar ha sido interpretado como una forma indirecta de insinuar a Beowulf que el enfrentamiento con Grendel devolvería la deuda que su padre contrajo con el rey o, si se quiere, podría haber llevado a los receptors del poema medieval a considerar esta obligación moral como el verdadero motivo del viaje del héroe a Dinamarca. Sea como fuere, la insinuación aparece clara y explícitamente desarrollada en ambas reelaboraciones; Hrothgar, por ejemplo, señala en la novela: «Ay... Sin embargo, los hechos generosos no quedan sin recompensa. Yo le salvé el pellejo y ahora tú vas a salvar los nuestros ¿a qué sí?» (pp. 81-82).

Un tratamiento parecido tiene el duelo verbal entre Beowulf y Unferth a cuenta de la contienda que enfrentó al primero con Breca en su juventud. Tanto la recreación cinema-

10 Todas las citas del Beowulf medieval proceden de la edición de Bruce Mitchell y Fred C. Robinson (1998); el único responsable de la traducción española es quien firma este trabajo. 
tográfica, como la versión novelada de Kiernan recogen todos los ingredientes del original y siguen de cerca la descripción maravillosa de la lucha de Beowulf con los monstruos marinos. Difieren, no obstante, cuando insinúan que en este episodio podría haber participado la madre de Grendel, representada por los tentáculos que aprisionan a Beowulf - como más tarde hará su enemiga - y lo arrastran hasta las profundidades, forzando así el retraso del héroe y la victoria de Breca. Además, en relación con la tendencia a ampliar o desarrollar meras insinuaciones del texto medieval, cabe referir la acusación de Beowulf hacia Unferth, en el sentido de que éste podría haber sido el causante de la muerte de miembros de su familia:

Breca næfre git $[\ldots]$ æt heaðolace

swa deorlice dæd gefremede [...]

peah ðu pinum broðrum to banan wurde

heafod mægum (11. 583b-588a)

Nunca consiguió [...] Breca [...] una proeza tan brava en la batalla [...] aunque tú te convertiste en homicida de tus hermanos, los miembros principales de tu clan.

Las versiones actuales transforman esta insinuación en afirmaciones directas, categóricas y, a todas luces, insultantes; así se pronuncia Beowulf:

... se dice de ti que eres inteligente, que no sabio, ojo, y que tienes una mente perspicaz. Y también se dice que mataste a tus hermanos cuando los sorprendiste acostándose con vuestra madre. Tengo entendido que en Götaland, mi tierra, os llaman Unferth el parricida (p. 89).

Otra modificación del poema apoyada en mecanismos intertextuales y en los propios 'espacios de indeterminación' del Beowulf medieval afecta a la presentación de Wealtheow, la reina danesa, quien desempeña la función de anfitriona que trata de reforzar los lazos sociales, y, como en el original (11. 620-628), es presentada en la película pasando la copa de unos invitados a otros; también la novela refuerza esta función cuando se describe en los términos siguientes:

La doncella [...] rellenó [la copa] y se movió entre las filas de daneses, vinculados a la casa real, y los guerreros gautas, ofreciéndosela alternativamente a unos y a otros [...] Al final, la reina convidó a Beowulf, dándole la bienvenida formal y expresando su agradecimiento a los dioses por haberle concedido su petición de que su pueblo se viera liberado (p. 91).

La prioridad de aportar el lado humano de los personajes lleva a los guionistas a representarla interpretando una balada y deja entrever la atracción mutua entre ambos personajes - obviamente ausente del texto medieval:

En ese momento el gauta alzó la copa e hizo un gesto de brindis hacia la reina, quien sonrió cálidamente al ver el ademán. Beowulf interpretó que había en 
ella algo más que mera gratitud, había un sentimiento cercano al deseo y a la invitación (p. 92).

Se trata en todos los casos de un recurso que tiene muy presente el texto medieval y demuestra un conocimiento profundo por parte de los guionistas y de la autora de la novela. Cuanto mayor sea también el conocimiento que el público tenga del poema anglosajón, mayor disfrute intelectual obtendrá de su visionado o de su lectura.

\subsubsection{Recursos literarios y estereotipos genéricos: del realismo sucio a la dark fantasy}

En secciones anteriores he recogido algunas propuestas críticas que destacan la tendencia de muchas recreaciones populares del mundo medieval a resaltar el aspecto sórdido, desordenado y cruel de la Edad Media, arrogándose la capacidad de ofrecer así una visión 'auténtica' y 'realista' del periodo, frente a representaciones idealizadas en las que predomina el componente cortesano o aventurero. También se ha mencionado, en línea con el objetivo escapista de estas recreaciones, su combinación con elementos propios del género fantástico. Es interesante señalar, en este sentido, que tanto la película como la novela mezclan componentes de ambas especies apelando a la experiencia literaria que de estos dos géneros tienen sus receptores.

Desde el principio se acude a a la versión estereotipada del mundo medieval como época de excesos, crueldades y violencia, en consonancia con el objetivo de mostrar el lado 'humano' de la leyenda. Ambas narraciones arrancan con la celebración de un banquete en Heorot, erigido como lugar consagrado a los festejos y al júbilo más desordenados (p. 8), en claro contraste con su función simbólica de prosperidad y unidad social en el Beowulf canónico:

Ond pær on innan eall gedælan geogum ond ealdum swylc him god sealde

buton folcscare ond feorum guwena (11. 71-73)

En su interior repartía con jovenes y ancianos todo lo que Dios le había dado; todo, excepto la propiedad comunitaria y las vidas humanas.

El propio Hrothgar - un venerable anciano y un rey generoso y sabio en Beowulfaparece como un monarca borracho y descuidado, que ronca ruidosamente cuando duerme la mona o emite sonoras flatulencias en su vigilia; además, se muestra por primera vez cubierto sólo con una sábana que, de forma indigna, deja entrever parte de su obeso cuerpo desnudo. Sus súbditos no son mucho más recatados cuando golpean las mesas con el puño o las copas y saltan sobre ellas pateándolas. Por otro lado, en su presentación individual destacan los defectos físicos y morales sobre otras cualidades; así Hondshew - un 'guerrero bien ceñido' en el original (gyrded cempa, 1. 2078a)—, es aquí «un feo gañán de físico tan imponente como Beowulf» (p. 63) que, antes de su anunciada muerte a manos de Gréndel, sólo tiene en mente a la joven Yrsa, por cuya barbilla desciende el nectar violáceo procedente del fruto que con sensualidad mordisquea, camino de sus amplios pechos (p. 64). 
Ni siquiera el propio Beowulf escapa a esta humanización desde la perspectiva del que se podría denominar 'realismo sucio'; su primera intervención en la película y, especialmente, en la novela de Kiernan, contrasta con la cortesía extrema de que hace gala en el original (11. 260-285). Aquí, sin embargo, aparece como un personaje chulo y fanfarrón, que se enfrenta a una magnífica tormenta imprecando a los mismísimos dioses: «iQué se ahoguen los muy condenados! [...] ¡Si todavía no se han dado cuenta de que no van a asustarme con cuatro gotas de lluvia y un poco de viento, bueno, entonces es que son tontos de remate!» (p. 57).

Llama la atención, en este sentido, el tratamiento que ambas versiones dan al encuentro entre Beowulf y el vigilante de la costa danesa: por un lado, de acuerdo con los parámetros 'realistas' manejados — hambrunas, violencia, impotencia del hombre ante la naturaleza - éste se presenta aterido, protegiéndose de la lluvia como puede y asando la rata que, insertada en su lanza, constituye su único alimento; por otro, destaca también la valoración psicológica que el guardián realiza a la vista del comportamiento del recién llegado. Como es bien sabido, en el original el centinela se percata enseguida de las cualidades que adornan al héroe: «Næfre ic maran geseah / eorla ofer eorpan ðonne is eower sum / secg on searwum» (11. 247b-249a) (Nunca he visto un guerrero tan noble sobre la tierra como la persona notable que hay entre vosotros; ese hombre con sus armas). Además, el vigilante aprende a discriminar «las palabras y las acciones» - gescad [...] worda ond worca (ll. 288b-289a) - distinguiendo el discurso pacífico de Beowulf, del porte militar y aguerrido que denotan su vestimenta y las armas que lleva consigo. En ambas reelaboraciones el mismo personaje no sólo no valora la dimensión heroica del recién llegado, sino que cuestiona también su capacidad y llega a insultarlo:

- Deberías saber, gauta, que el monstruo que nos atormenta es fuerte y rápido.

- También yo - replicó Beowulf.

- Sí, claro, como todos los demás que vinieron a luchar contra él, y ahora están muertos. Todos. La verdad es que pensaba que no quedarían héroes tan tontos como para acudir a esta tierra y morir por nuestro oro (p. 62).

En general, frente a la generosidad que inspira a los principales personajes del original, aquí todos, desde el monarca y sus súbditos hasta el mismísimo héroe, se mueven por la codicia y la ambición. Beowulf, por ejemplo, se imagina «coronado como señor de este solar, un soberano apropiado para regir a los daneses, más que un obeso anciano [Hrothgar], demasiado enfermo y más interesado en las granjeras y el hidromiel que en el bienestar de su reino» (p. 157). Esta ambición desmedida, e irrespetuosa con su anfitrión, contrasta con el respeto escrupuloso que el héroe medieval muestra por el derecho de los herederos legítimos a ocupar el trono, tanto en Dinamarca (a pesar de que Hrothgar lo acepta como hijo), como en el reino gauta. Por otro lado, en las reelaboraciones la madre de Grendel obtendrá provecho de este defecto moral para atraer al héroe, perpetrar su venganza y perpetuarse, manteniendo así su castigo sobre los daneses.

Como he señalado, esta reinterpretación de algunos fragmentos del original medieval a partir de los estereotipos genéricos del 'realismo sucio' convive en las recreaciones 
populares con el recurso a elementos propios de los géneros fantásticos, aderezados con componentes del género de terror. De hecho Caitlín R. Kiernan es consumada autora de novelas de dark fantasy: un tratamiento al que, por otro lado, se presta el poema medieval. Es en relación con los antagonistas del héroe, Grendel y su madre, donde mejor se manifiesta este extremo. Así, frente a las conexiones bíblicas de Grendel, claro descendiente de la estirpe de Caín (11.102-108), en la novela de Kiernan se trata de una misteriosa criatura nocturna: «que no era ni hombre ni animal, sino seres antiguos, descendientes de gigantes, trolls y otros entes aun peores que durante la vigilia pululaban por fangales y marjales prohibidos» (p. 24). Otras veces se presenta en intersección con el universo mitológico nórdico (véase 2.2.3.), como «un ente de antaño, de los días previos a que los dioses aprisionaran a Loki [...] y a su plebe inmunda» (p. 39). Cabe señalar, en este sentido, que la presentación de Grendel en la novela - y su visión en la película de Zemeckis - resultan tan deshumanizadas como el monstruo del poema medieval (figura 1). El nuevo Grendel tiene largos colmillos y garras, ojos de color grisaceo, suelta un resuello de vapores fétidos por sus labios negros y por las aletas dilatadas de la nariz, desplaza su cuerpo, que crece y disminuye de tamaño, a gran velocidad, a la vez que chilla y emite sonidos repulsivos que, en la novela, evocan «el ocaso de los reinos, el estertor de la muerte, el dolor y las grandes grietas que desgarrarían la tierra el día del fin del mundo» (p. 38).

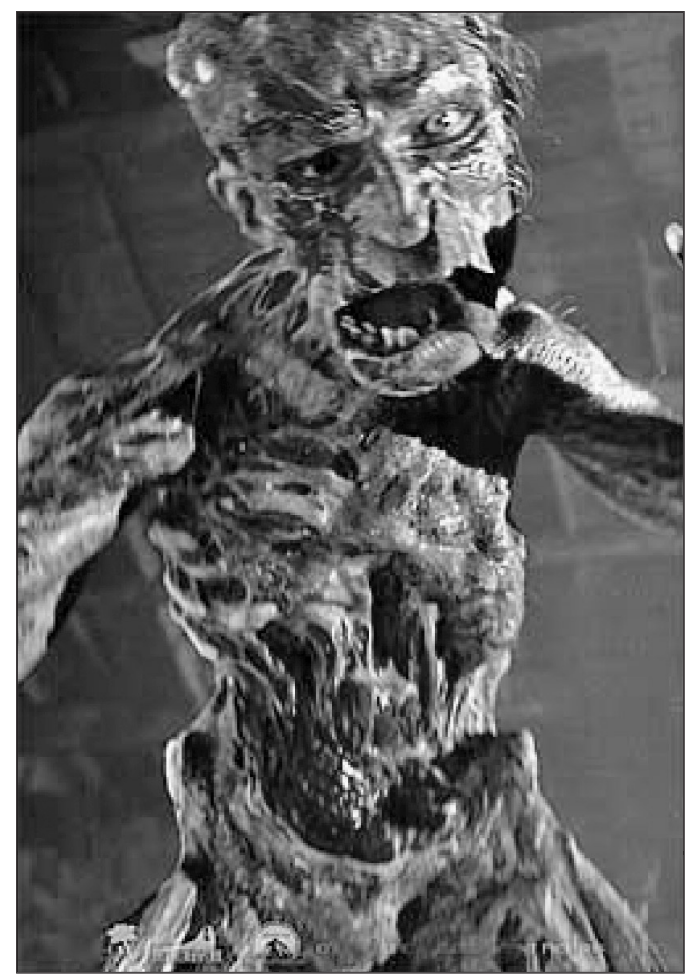

Figura 1: Grendel en la película Beowulf de Zemeckis (CC) Paramount Pictures and Shangri-La Entertainment) 
En cuanto a su madre, la perspectiva seductora y sensual que obtienen los personajes masculinos - ya mencionada - se complementa con explicaciones externas sobre su origen. Se trataría de la última superviviente de una raza de gigantes, trolls y dragones, «generada en los primeros días de la creación [...] venerad[a] [...] como madre Tierra, como Nerpuz y algunas veces como Niord de los ases y otras como la esposa de éste y diosa del mar» (p. 162). Estamos ante una curiosa confluencia del elemento fantástico, con el papel religioso de la madre tierra entre los antiguos germanos, que algunos identifican con la diosa Nerthus y otros con antiguas creencias en dioses familiares, cuyo culto fue sustituido por dioses de la guerra (Bernárdez 2002: 143-158). ${ }^{11}$ ¿Hasta qué punto no se trata de una diosa superviviente de la antigua religión, que, en su función maternal y procreadora, busca naturalmente perpetuarse y sobrevivir, seduciendo a hombres fuertes y poderosos?

\subsubsection{Recursos culturales: la mitología nórdica}

No quiero terminar este recorrido por las estrategias de reconversión del Beowulf medieval en la ficción popular del siglo XXI sin aludir brevemente a otro aspecto - no menos estereotipado que los otros - del que, en general, suele abusarse en las recreaciones de la Edad Media: se trata del universo mitológico nórdico, ya apuntado al tratar sobre la presentación de la madre de Grendel. Por su carácter erudito y su transmisión escrita, este recurso se emplea de forma profusa en la adaptación novelada de Caitlín Kiernan, en comparación con la versión cinematográfica de Zemeckis. Posiblemente, la inserción de la novela en el entorno genérico de la dark fantasy, cuyo público está familiarizado con este universo mitológico, haya favorecido también su despliegue, en claro contraste con el objetivo más comercial de la película. Además del contraste entre ambas versiones, se establecen marcadas diferencias con un texto medieval que recibimos impregnado de un sentido cristiano innegable, coexistente con referencias, más o menos fosilizadas, a distintos aspectos de la mitología nórdica. Así, el esfuerzo de los guionistas por contener las referencias paganas de la película y hacerlas cohabitar, en la segunda parte, con la conversión al cristianismo de Unferth y Wealtheow puede entenderse como su forma de recrear la convivencia de las dos religiones en el original, y contrasta con el derroche de referencias mitológicas en la novela de Kiernan - aunque, fiel al guión que la inspira, la autora mencione también el advenimiento del cristianismo en la parte fïnal del texto: «Quizá por eso tantos hombres dan la espalda a Odín y a sus hermanos [...] y abrazan a ese Cristo romano asesinado y a ese dios sin nombre del que dicen que es su padre» (p. 227), señala Beowulf en el ocaso de su reinado.

Cabe asignar, en mi opinión, dos funciones distintas a las referencias a la mitología nórdica en la novela. Por un lado, algunas están directamente imbricadas en la trama,

11 Así lo han propuesto, en relación con el poema medieval, críticos como Alfano (1992), Battaglia (1991) o Grisby (2005), cuyos trabajos son citados por Kiernan en una nota final. En la misma novela, Sigga, la vidente islandesa, cuestiona ante Unferth este origen: «Puede que fuera adorada como diosa hace tiempo. Algunos la llaman Njord, esposa de Niord, y otros la han llamado Nerthus, la madre tierra. No lo creo ... Pienso que es algo que ha llegado desde el mar, y que es un monstruo nacido en los palacios de los Ases» (p. 253) 
ya sea porque establecen un marco legendario en el que el lector puede establecer los acontecimientos narrados, ya porque puntúan o acompañan a las acciones del héroe; por otro, abundan también breves referencias a los dioses y leyendas en las intervenciones dialogadas de algunos personajes, o muchas veces, en las descripciones. En relación con las primeras, la novela se inicia con un resumen de la formación del universo nórdico, que incluye todos los elementos clásicos recogidos en el poema éddico Völuspá y en la recreación posterior realizada por Snorri Sturluson en «Gylfaginning», el primer libro de la Edda Menor (1220-1230). ${ }^{12}$ De este modo, encontramos todos los elementos característicos: la combinación, en el vacío primigenio, de los principios contrapuestos representados por el fuego (Muspelheim) y el hielo (Niflheim), que generan al gigante Ymir; su derrota por los antecesores de los dioses — Odín, Vili y Ve-, descendientes de Buri y de la vaca Audhumla, y la formación de los distintos elementos del mundo (Midgard) a partir de las partes de su cuerpo (pp. 19-20). Kiernan completa este marco ubicando en el Midgard a la estirpe de los héroes, cuya recompensa es la fama, el honor y, tras una muerte heroica, su recepción por Odín en el Valhala. De hecho, las referencias a este paraíso guerrero recorren toda la novela, como elemento más popular de la mitología nórdica, $y$, aunque los lectores sepan que a sus protagonistas masculinos los mueve la ambición y el poder, Beowulf no deja de transmitir sus creencias en esta recompensa.

Esta aspiración del héroe tendrá cumplimiento en el epílogo, cuando, tras la descripción del funeral de Beowulf, se mencione su futuro recibimiento en el palacio de Odín, donde esperará el momento de su liberación cuando llegue el Ragnarök (pp. 346-347). El propio epílogo contiene otra referencia a la mitología nórdica que, además de actuar como marco externo de la trama, puntúa las acciones del héroe: se trata de las nornas -Urd, Skuld y Verdandi - que, situadas bajo el fresno Yggdrasil - la cosmogonía de este corpus mitológico — «tej[en] y dibuj[an] las vidas de todos los hombres y todas las mujeres, urdiendo la existencia a partir del caos y de las infinitas posibilidades» (p. 333). $\mathrm{Su}$ presencia en otras secciones de la novela tampoco es gratuita, sino que, en relación con la importancia que adquieren las figuras femeninas en la narración, son continuamente citadas por los héroes masculinos como tejedoras de su destino. Es Wiglaf, sin embargo, el personaje más consciente del papel que las nornas han de jugar en su trayectoria; por un lado, plantea abiertamente su conexión simbólica con la naturaleza y su relación con el poder femenino de la madre de Grendel, cuando observa tres grandes robles, cuyas raíces son «el gran tapiz del destino que han tejido las nornas» (p. 286). Por otro lado, las nornas adquieren una función importante al final de la novela, cuando, en relación con el incierto destino de Wiglaf, se deja el desenlace en sus manos:

Y las nornas, Urd, Verdandi y Skuld, las tres parcas que laboriosamente tejen las vidas bajo las raíces de Yggdrasil, observaron cómo se componía poco a poco otro tapiz fuertemente anudado en sus telares. Cada hilo era un objeto

12 De hecho, aunque no lo cite, esta presentación inicial de los mitos nórdicos es bastante fiel al epítome medieval de Sturluson; Kiernan remite, sin embargo, al manual de John Lindow, Norse Mythology: A Guide to the Gods, Heroes, Rituals and Beliefs (2001), recomendado como lectura al final del libro. 
precioso para ellas; por eso tejieron y esperaron con la paciencia de quien tiene a su disposición toda la eternidad (p. 339).

Un último aspecto procedente de la mitología nórdica, también claramente imbricado con la acción de la novela, es la descripción del sacrificio de Odín, tal como aparece tallado en la viga de madera de la que cuelga el brazo amputado de Grendel, como un recuerdo de la hazaña del héroe, pero también - manchada por la sangre que gotea desde la extremidad del monstruo - como anticipación o presagio del sacrificio que, años después, el propio Beowulf habrá de cometer para salvar a sus súbditos de la maldición del dragón. La descripción del mito remite fielmente al poema éddico Hávamál:

Wiglaf reconoció la escena representada en la talla, Odín colgando de las ramas del Fresno del Mundo, Yggdrasil, atravesado por su propia lanza. Nueve noches y nueve días de dolor para conseguir ganar la sabiduría de las nueve canciones que le garantizarían el poder de atravesar los nueve reinos y el don de las dieciocho runas y un trago del precioso hidromiel de los gigantes (p. 146)

En la versión novelada abundan, finalmente, referencias breves a otros aspectos de la mitología nórdica, ya sea en forma de imprecaciones puestas en boca de los personajes, ya sea en las descripciones. Cabe destacar la gran cantidad de menciones mitológicas de este tipo, hasta el punto de que el libro incluye un glosario final con más de noventa entradas. Esta variedad da también idea de que no se trata sólo de los aspectos más conocidos o estereotipados de este corpus mitológico. Así, por seleccionar algunos, se menciona al dragón Nidhogg, el terrible roedor, enroscado en las raíces del fresno Yggdrasil. Se alude también varias veces a la genealogía de los monstruos, descendientes de Loki y de la serpiente del mundo, Jörmungand, que pueblan el imaginario de los héroes y de sus antagonistas. También se cita el mundo mágico y misterioso de los elfos negros de Nidafiol, cuyo poder, tal como la vidente islandesa Sigga transmite a Unferth, ha sido traspasado al cuerno de oro (pp. 250-251), o se menciona durante el Ragnarök que los monstruos serán liderados por Fenrir cuya cadena no era irrompible, como, siguiendo a Sturluson, otras cosas imposibles que los elfos supieron crear: la barba de una mujer, las raíces de una montaña, la respiración de un pez (p. 267). Finalmente, cabe destacar la alusión a aspectos de la mitología nórdica en ciertas descripciones que, aderezadas del componente mítico, adquieren un mayor calado poético: así, la tormenta marina que Beowulf encuentra en su viaje hasta Dinamarca es presentada como resultado del trabajo de las nueve hijas de Ægir, el dios del mar (p. 55), y el gélido viento del norte procede de la acción del águila gigante Hræsvelg, que bate sus alas «desde su altísimo risco en los espacios superiores deYggdrasil» (p. 233). Una función muy semejante cabe atribuir a la mención de lugares geográficos del mundo nórdico, como Gandvisk (el Báltico), el estrecho de Jotlandshat, entre Noruega, Dinamarca y Suecia, o a otras realidades del mundo germánico, como los nombres de algunas tribus - los Vándalos y los Wylfingos, entre otros - o la designación de los meses invernales: Frermánuðr y Mörsugur. 


\section{CONCLUSIÓN}

Parte de la crítica vertida sobre la película de Robert Zemeckis coincide en valorar su engarce con el poema original y, mas allá de una fidelidad concreta, su imbricación general con el horizonte literario heroico-medieval. Para Bermejo, por ejemplo, se trata de «un respeto escrupuloso por los ingredientes de las leyendas épicas tradicionales» que, «convincentemente orquestados [...] lo aproximan a un planteamiento casi clásico» (2007: 54). Cabe señalar también que esta aceptación de la convención medieval no es una novedad cuando se compara con otras recreaciones contemporáneas del pasado histórico para la cultura popular. Es clave, en este sentido, entender que cualquiera de ellas precisa la colaboración activa de sus receptores, quienes aceptan una especie de 'pacto narrativo'; éste supone, por un lado, aceptar sus límites como recreaciones y, por otro, entender la importancia que tiene para su comprensión y disfrute «un conocimiento mínimo del repertorio de fórmulas y arquetipos utilizados por el imaginario popular para la representación de la Edad Media» (Gómez Calderón 2002: 87). De hecho, el desconocimiento de estos elementos por parte del público puede hacer que las reelaboraciones pierdan su razón de ser, de modo que la lectura palimpséstica se convierte en necesaria, si no para dotarlas de sentido pleno, sí para obtener una lectura más enriquecedora (Quintana Docio 1990: 192; también: Martín Fernández 2001).

En la introducción he resaltado algunas convenciones generales de las recreaciones contemporáneas de tema medieval que también caracterizan a aquellas que tienen cono base al poema heroico Beowulf: (i) su finalidad escapista y, en ocasiones, crítica con los excesos o faltas morales de las sociedades contemporáneas, a veces alineadas con ideologías neo-conservadoras; (ii) su construcción sobre la base de estereotipos, también derivada de la dificultad de aprehender un pasado disuelto en su propia dimensión narrativa y textual; o, finalmente, (iii) la incorporación de nuevas perspectivas - más humanas o, incluso, paródicas - en relación con las fuentes que les sirven de base. Estos tres ingredientes están, sin duda, presentes en la versión cinematográfica de Beowulf dirigida por Robert Zemeckis a partir del guión de Neil Gaiman y Roger Avary y en la novela homónima de Caitlín R. Kiernan. Creo, sin embargo, que ambas reelaboraciones del texto canónico añaden otros factores. Su construcción se basa, por un lado, en las expectativas de las recreaciones populares de lo medieval y, de este modo, sus límites genéricos oscilan entre lo que hemos llamado 'realismo sucio' - la Edad Media sórdida, cruel y embrutecida - y el género popular conocido como dark fantasy, basado en la combinación de elementos mágicos o sobrenaturales con efectos terroríficos. Ambos extremos se desarrollan aprovechando los propios contenidos del Beowulf medieval, de modo que determinados vacíos o lagunas del poema son utilizados para buscar motivaciones humanas a los comportamientos del héroe y sus antagonistas. Por otro lado, ambas recurren a la intertextualidad y sitúan, irónicamente, el propio poema medieval como referente (hipotexto) necesario para interpretar algunas escenas de la película y, dada su construcción escrita, bastantes pasajes de la novela: desde menciones indirectas al Beowulf canónico, incorporado como poema épico en los propios márgenes de las dos versiones, hasta juegos especulares con los contenidos de las digresiones que aparecen en el texto medieval, pasando por la utilización de las lagunas del original - espacios de indeterminación que 
dejan abierta su interpretación. A estos elementos cabe añadir las referencias ubicuas a la mitología nórdica como parte esencial de la trama en la novela de Kiernan. Todos estos ingredientes demuestran el respeto y el conocimiento profundo del texto medieval y de las coordenadas de la poesía heroica germánica por parte de los guionistas y la autora, a la vez que apelan a los espectadores y lectores a recurrir también a ese conocimiento para disfrutar plenamente de las obras, añadiéndoles así una dimensión culta o intelectual.

\section{REFERENCIAS}

ALFANO, Christine: «The issue of feminine monstrosity: A reevaluation of Grendel's mother». Comitatus 23 (1992): pp. 1-16.

ÁLVAREZ DE MOLL, Daniel: «Beowulf». Making of. Cuadernos de cine y educación 54 (2008), pp. 17-24.

ALLAN, Syd: «Beowulf. Cinematic Translations». Beowulf Translations.net. http://www. beowulftranslations.net/movie.shtml [2009-01-15].

ALONSO, Juan J., Enrique A. MASTACHE y J. ALONSO: La Edad Media en el cine. Madrid: T\&B editores, 2007.

BATTAGLIA, Frank: «The Germanic Earth Goddess in Beowulf». Mankind Quarterly 31.4. (1991), pp. 415-446.

BERNÁRDEZ, Enrique: Los mitos germánicos. Madrid: Alianza, 2002.

BERMEJO, Alberto: «Épica tridimensional. Beowulf». El Cultural (22-11-2007), p. 54.

BUENO ALONSO, Jorge Luis: «Leodum liðost ond lofgeornost. La poesía épica de Beowulf en nuevos formatos gráficos y visuales». ES 28 (2007-2008), pp. 47-72.

COTTA VAZ, Mark y Steve STARKEY: The Art of Beowulf. New York: Chronicle Books, 2007.

DUBY, Georges: An 1000, an 2000: sur les traces de nos peurs. París: Textuel D.L., 1995 [Versión española: Año mil, año 2000. La huella de nuestros miedos. Santiago de Chile: Andrés Bello, 1995].

ECO, Umberto et al.: La nueva Edad Media. Madrid: Alianza, 1974.

FERNÁNDEZ PRIETO, Celia: «Relaciones pasado-presente en la narrativa histórica contemporánea» en J. Romera Castillo et al. eds. 1996, pp. 213-221.

FRADENBURG, Louise: «'So that we may speak of them'. Enjoying the Middle Ages». New Literary History 28.2. (1997), pp. 205-230.

FRANTZEN, Allen J. y John D. NILES (eds.): Anglo-Saxonism and the Construction of Social Identity. Gainesville: University of Florida Press, 1997.

GAIMAN, Neil y Roger AVARY: Beowulf: The Script Book. New York: Harper Collins, 2007.

GALVÁN, Fernando: «Rewriting Anglo-Saxon: Notes on the Presence of Old English in Contemporary Literature». Selim 2 (1992), pp. 70-90.

GARCÍA GUAL, Carlos: La antigüedad novelada. Las novelas históricas sobre el mundo griego y romano. Barcelona: Anagrama, 1995.

GENETTE, Gérard: Palimpsestes. Paris: Editións du Seuil, 1962 [Versión española: Palimpsestos. La literatura en segundo grado (trad. C. Fernández Prieto). Barcelona: Taurus, 1989]. 
GÓMEZ CALDERÓN, Ma José: Los 'otros Beowulfs'. Reelaboraciones contemporáneas. Tesis doctoral inédita. Sevilla: Universidad de Sevilla, Dpto. de Literatura inglesa y norteamericana, 2002.

GÓMEZ REDONDO, Fernando: «Edad Media y narrativa contemporánea». Atlántida 3 (1990), pp. 28-47, 266-280.

GRISBY, John: Beowulf and Grendel: The Truth Behind England's Oldest Legend. London: Watkins, 2005.

GUZMÁN GONZÁLEZ, Trinidad: «MacTiernan, John 1999. El guerrero número 13». Selim 9 (1999), pp. 220-225.

HASENFRATZ, Robert J.: Beowulf Scholarship: An Annotated Bibliography, 1979-1990. New York: Garland, 1993.

JAMENSON, Frederic: Postmodernism or the Cultural Logic of Late Capitalism. London: Verso, 1984.

KAVENEY, Roz: «Beowulf». Strange Horizons.

$<$ www.strangehorizons.com/reviews/2007/11/beowulf.shtml > [2009-01-15]

KIERNAN, Caitlin R.: Beowulf. New York: Harper Collins, 2007 [Versión española: Beowulf (trad. José Miguel Pallarés, Mª Jesús Sánchez y José Calles; prólogo de Laura Gallego). Madrid: Espasa Calpe, 2007].

LINDOW, John: Norse Mythology: A Guide to the Gods, Heroes, Rituals and Beliefs. Oxford: Oxford University Press, 2001.

MAGENNIS, Hugh: «Michael Crichton, Ibn Fadlan, Fantansy Cinema: Beowulf at the Movies». Old English Newsletter 35.1. (2001), pp. 34-38.

MARTÍNEZ FERNÁNDEZ, José Enrique: La intertextualidad literaria. Madrid: Cátedra, 2001.

MITCHELL, Bruce y Fred C. ROBINSON (eds.): Beowulf. An Edition. Oxford: Blackwell, 1998.

OLEZA SIMÓ, Joan: «Una nueva alianza entre historia y novela. Historia y fícción en el pensamiento literario del fin de siglo», en J. Romera Castillo et al. eds. 1996, pp. 81-95.

OSBORN, Marijane: «Translations, versions, illustrations» en Robert E. Bjork y John D. Niles (eds.). A Beowulf Handbook, Lincoln: University of Nebraska Press, 1997, pp. 341-382.

OSBORN, Marijane: «Annotated List of Beowulf Translations». The Arizona Center for Medieval and Renaissance Studies website:

<www.asu.edu/clas/acmrs/web_pages/online_resources/> [2008-12-09]

PROPP, Vladimir: El epos heroico ruso (trad. A. Gómez Olea). Madrid: Fundamentos, 1955 [1983].

QUINTANA DOCIO, F.: «Intertextualidad genética y lectura palimpséstica». Castilla. Estudios de Literatura 15 (1990), pp. 169-182.

ROMERA CASTILLO, José et al. (eds.): La novela histórica a finales del siglo XX. Madrid: Visor, 1996.

SCRAGG, Donald y Carole WEINBERG: Literary Appropiations of the Anglo-Saxons from the Thirteenth to the Twentieth Century. Cambridge. Cambridge University Press, 2000. 
SHIPPEY, Tom S. y Andreas HAARDER (eds.): Beowulf: The Critical Heritage. London: Routledge, 1998.

SUTTON, John William, Beowulfiana: Modern Adaptations of Beowulf. The Camelot Project at the University of Rochester website:

<www.library.rochester.edu/camelot/BeowulfBooklet.htm> [2008-12-09].

WARNER, Marina: Managing Monsters. Six Myths of Our Time. The Reith Lectures 1994. London: Vintage, 1994.

ZEMECKIS, Robert: Beowulf. Paramount Pictures and Shangri-La Entertainment, 2007. 
